$\stackrel{N / N}{=}$

Global journals Inc.

की

\title{
Factors Associated with Knowledge Regarding Uterine Prolapse among Women Attending Gynecology Outpatient Department of Tertiary Care Teaching Hospital
}

By Nirmal Raj Marasine, Sabina Sankhi, Rajendra Lamichhane, Sonu Pakhrin, Sangit Maharjan, Saroj Sankhi, Nabin Raj Marasini \& Sumitra Shrestha

Pokhara University and Western Health Science Academy

Abstract- Background: Uterine prolapse (UP) is a common reproductive health problem in lowmid-income countries such as Nepal. The current study aimed to explore the factors associated with knowledge regarding UP among women attending the gynecology outpatient department of tertiary care teaching hospital.

Methods: A cross-sectional study was conducted among patients visiting the gynecology outpatient department of tertiary care teaching hospital in Nepal from July to September, 2016 using a purposive sampling technique. A suitably designed and validated questionnaire of knowledge consisting of 20 questions was used to determine the knowledge scores. Descriptive statistics and bivariate analysis were used; a p-value $<0.05$ was taken as significant in multivariate analysis.

Keywords: Associated factors, Gynecology, Knowledge, Tertiary care teaching hospital, Uterine prolapse, Women.

GJMR-E Classification: NLMC Code: WP 454

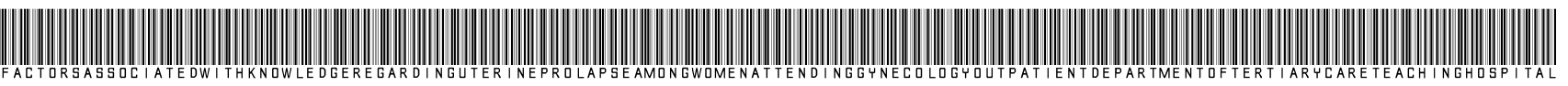

Strictly as per the compliance and regulations of:

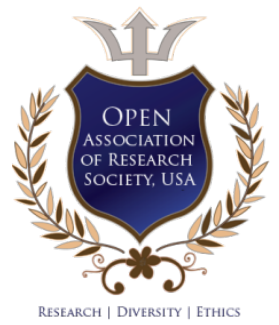

(c) 2020. Nirmal Raj Marasine, Sabina Sankhi, Rajendra Lamichhane, Sonu Pakhrin, Sangit Maharjan, Saroj Sankhi, Nabin Raj Marasini \& Sumitra Shrestha. This is a research/review paper, distributed under the terms of the Creative Commons AttributionNoncommercial 3.0 Unported License http://creativecommons.org/licenses/by-nc/3.0/), permitting all non-commercial use, distribution, and reproduction in any medium, provided the original work is properly cited. 


\title{
Factors Associated with Knowledge Regarding Uterine Prolapse among Women Attending Gynecology Outpatient Department of Tertiary Care Teaching Hospital
}

\author{
Nirmal Raj Marasine ${ }^{\alpha}$, Sabina Sankhi ${ }^{\sigma}$, Rajendra Lamichhane ${ }^{\circ}$, Sonu Pakhrin ${ }^{\omega}$, Sangit Maharjan ${ }^{*}$, \\ Saroj Sankhi ${ }^{\S}$, Nabin Raj Marasini ${ }^{x} \&$ Sumitra Shrestha ${ }^{v}$
}

\begin{abstract}
Background: Uterine prolapse (UP) is a common reproductive health problem in low-mid-income countries such as Nepal. The current study aimed to explore the factors associated with knowledge regarding UP among women attending the gynecology outpatient department of tertiary care teaching hospital.
\end{abstract}

Methods: A cross-sectional study was conducted among patients visiting the gynecology outpatient department of tertiary care teaching hospital in Nepal from July to September, 2016 using a purposive sampling technique. A suitably designed and validated questionnaire of knowledge consisting of 20 questions was used to determine the knowledge scores. Descriptive statistics and bivariate analysis were used; a $p$-value $<0.05$ was taken as significant in multivariate analysis.

Results: The majority of the study participants (40.76\%) aged between $18-30$ years, $48.46 \%$ were Brahmin, $91.53 \%$ were married, $46.15 \%$ had a primary level of education, and $83.07 \%$ resided in central Nepal. Seventy percent had heard about UP. More than half of the participants $(75 ; 57.69 \%)$ had a satisfactory level of knowledge and 55 (42.30\%) had a good level of knowledge of uterine prolapse. Age $(p=0.014)$, education $(p=0.008)$, occupation $(p=0.03)$, and ethnic group (0.024) were found significantly associated with the level of knowledge among women.

Conclusion: Our study showed that the level of knowledge on UP among women of reproductive age group is satisfactory, and is attributed to factors such as age, education, occupation, and ethnic group.

Keywords: Associated factors, Gynecology, Knowledge, Tertiary care teaching hospital, Uterine prolapse, Women.

Corresponding Author $\alpha$ : Western Health Science Academy, Pokhara, Kaski, Nepal. e-mail: nirmalmarasine@gmail.com

Author $\alpha$ o: School of Health and Allied Sciences, Pokhara University, Kaski, Nepal.

Author $\rho$ : Department of Public Health, Asian College for Advance Studies, Lalitpur, Nepal.

Author $\omega ¥ v$ : Divine Healthcare Pvt. Ltd. Bharatpur, Nepal.

Author \&: Department of Animal Science, Dhaulagiri Polytechnic Institute, CTEVT, Baglung, Nepal.

Author $\chi$ : Department of Public Health, La Grande international College, Pokhara, Kaski, Nepal.

\section{INTRODUCTION}

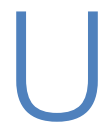
terine prolapse (UP), a reproductive health problem, is characterized by obtrusion of the uterus partially or wholly into the vagina, which occurs when pelvic floor muscles and ligaments become weak and no longer can support the uterus [1]. It is the most often reported cause of poor health among women of reproductive age (15-49) and postmenopausal women (45-49 years) around the globe [2]. Its global prevalence ranges from 2-20\%, whereas that in Nepal varies according to ecological zones such as 20 to $37 \%$ in the Terai (plain) region, $27.4 \%$ in the central and eastern hilly region, and $25 \%$ in the far western hilly region $[3,4]$. Despite the fact that it is preventable and curable, it holds the major global burden of morbidity and mortality among women [5]. In Nepal, more than 1 million women suffer from uterine prolapse, and most belong to the reproductive age group [6]. Nepalese women have more workload than men, since the traditional gender division of labor encourages women to concentrate more on their reproductive role and household activities, wherein men are free to move to different places for work [4, 7]. Early marriage, high parity, heavy lifting during and after pregnancy, early return to work after parturition, older age at last birth, postmenopausal status, and lack of sufficient rest and nutritious food contribute to high rates of UP $[8,9]$. More than $85 \%$ of Nepalese women reports vaginal lump, difficulty working, sitting, walking, urinary incontinence, vaginal discharge, loss of libido, and painful intercourse as common symptoms of UP [10]. UP affects many aspects of the quality of life of women, ranging from physical discomfort to psychological, social, and sexual lifestyle limitations. Supplementary to these, Nepalese women with UP faces family and societal discrimination, which further deteriorates their quality of life $[3,11]$.

Despite the high prevalence of UP in Nepal, it has not been addressed satisfactorily. Most women hide UP problems being conscious of the embarrassment, lack of family support, unsuccessful treatment, and high 
cost of treatment [12]. In Nepal, family planning services and maternal health care are providing regular services for public health promotion. Although various national, international, and non-governmental organizations have conducted specific awareness programs since 2005, to reduce the problem through outreach camps, health institutions, female community health volunteers, and mass media, a knowledge gap remains among women about UP [10, 13]. Even women who are aware of UP, its treatment, and access to healthcare often lag to seek it because of shyness of genital exposure, fear of abandonment by their husbands, and traditional beliefs that surgery will make them weaker [14]. It has been reported that $52.9 \%$ of Nepalese women are lacking knowledge on UP, and only $37.5 \%$ have thorough knowledge about this condition [2, 10]. A lack of appropriate and adequate knowledge regarding UP and its prevention often results in delayed care and safety measures [11]. The current study therefore aimed to explore the factors associated with knowledge regarding uterine prolapse among women attending the gynecology outpatient department of Chitwan Medical College Teaching Hospital. Our study is timely and relevant, and the findings will be helpful for understanding symptoms and knowledge among women with UP. Moreover, it will aid in the development of evidence-based health promotion programs for the prevention of UP in its early stage among the general population of women in Nepal.

\section{il. Methodology}

\section{a) Ethics}

Ethical approval of this study was obtained from the Chitwan Medical College- Institutional Review Committee (CMC-IRC) (Ref no: CMC-IRC-43) and written informed consent was obtained from each participant. Additionally, the study protocol presented no risk or harm to the participants and the method of consenting was approved by the IRC. Personal details of the participant were kept confidential, and anonymity was maintained.

b) Design

This was a hospital-based cross-sectional study.

\section{c) Population}

Participants aged $\geq 18$ years visiting the gynaecology outpatient department of Chitwan Medical College (Chitwan, Nepal) between July and September 2016 were included in the study. Pregnant or lactating mothers, participants with a psychiatric disorder, from other departments, and those unable to communicate and understand the Nepali language were excluded.

\section{d) Sample size}

A sample size of 130 was taken to study the factors associated with knowledge regarding UP using a purposive sampling method.

\section{e) Data collection}

The data on pre-existing knowledge of 130 participants were collected using a pre-validated questionnaire [2] through an interview method. A standard data collection form was built for collecting data on sociodemographic information. There were 20 questions for assessing knowledge. The English form of the questionnaire was translated into Nepali and pilot tested on $10 \%$ of the sample size of a similar setting who met our inclusion and exclusion criteria, and the reliability using Cronbach's alpha test was $\alpha=0.8$. Participants involved in the pilot were not included in the main study. Answer for each question regarding knowledge on UP was scored one for correct and zero for incorrect.

\section{f) Statistical analysis}

Data were entered in MS Excel 2013. The entered data were transferred to SPSS version 20 for further analysis. Univariate, bivariate, and multivariate analyses were performed. Bivariate analysis of independent variables with the dependent/outcome variable was performed by cross-tabulation and testing with Pearson Chi-square. Variables found significant in the bivariate analysis were included in a multivariate analysis and fitted using binary logistic regression (enter method) with knowledge as outcome variable. A measure of association was presented as an odds ratio (OR) with a 95.0\% confidence interval $(\mathrm{Cl}) . \mathrm{P}<0.05$ was considered statistically significant.

\section{Results}

Table 1: Sociodemographic characteristics of participants $(n=130)$

\begin{tabular}{llc}
\hline Characteristics & Categories & $\mathrm{n}(\%)$ \\
\hline Age & $18-30$ years & $53(40.76)$ \\
& $31-40$ years & $42(32.30)$ \\
Marital Status & $41-50$ years & $29(26.92)$ \\
& Married & $119(91.53)$ \\
Education & Divorced & $5(3.84)$ \\
& Widowed & $6(4.61)$ \\
& llliterate & $24(18.46)$ \\
& Primary Level & $60(46.15)$ \\
& Secondary Level & $27(20.76)$ \\
\hline
\end{tabular}




\begin{tabular}{llc}
\hline \multirow{3}{*}{ Ethnic Group } & Higher secondary or above & $19(14.61)$ \\
& Brahmin & $63(48.46)$ \\
& Chhetri & $19(14.61)$ \\
Development Region & Janajati & $13(10.0)$ \\
& Dalit & $35(26.92)$ \\
Occupation & Eastern & $4(3.07)$ \\
& Central & $108(83.07)$ \\
& Western & $18(13.84)$ \\
Monthly Income & Housewife & $97(74.61)$ \\
& Agriculture & $49(37.69)$ \\
Susiness & $11(8.4)$ \\
Source of Information on UP* & $<$ Rs.10,000 & $16(12.3)$ \\
& $<$ Rs.25,000 & $23(17.7)$ \\
& $>$ Rs 25,000 & $59(45.38)$ \\
Heard of UP & $\geq 50,000$ & $21(16.2)$ \\
& Mass Media & $27(20.8)$ \\
& Friends/ Relatives & $84(66.92)$ \\
& FCHVs & $48(36.92)$ \\
& Health Workers & $34(26.15)$ \\
\end{tabular}

*Multiple response

Abbreviation; UP: Uterine Prolapse, FCHVs: female community health volunteers

Among the 130 subjects, the majority of the study participants (53; 40.76\%) aged between $18-30$ years, where most of them (63; 48.46\%) were Brahmin. The study participants were predominantly married (119; $91.53 \%)$ and majority of them $(60 ; 46.15 \%)$ had a primary level of education. Most of the participants (108; 83.07\%) resided in central Nepal. Housewife (97; $74.61 \%$ ) was the most frequently reported occupation.
Most of the participants $(59 ; 45.38 \%)$ had monthly income less than Rs 2500. The majority of the participants (66.92\%) reported mass media as the main source of information, followed by friends/relatives (36.92\%) and FCHVs (26.15\%). Seventy percent of the participants reported that they had heard of UP, as depicted in Table 1.

Table 2: Knowledge on Symptoms, Preventive Measures, and Risk Factors of Uterine Prolapse $(n=130)$

\begin{tabular}{llr}
\hline Characteristics & Categories & $\mathrm{n}(\%)$ \\
\hline Symptoms* $^{*}$ & Difficulty in lifting loads & $125(96.15)$ \\
& Lower abdominal pain & $101(77.69)$ \\
& Sagging uterus & $98(75.38)$ \\
& Pain during sexual activity & $92(70.76)$ \\
& Difficulty controlling urine & $90(69.23)$ \\
Preventive measures* & Odorous discharge & $85(65.38)$ \\
& Not lifting heavy loads during Postnatal period & $130(100)$ \\
& Eating nutritious food during pregnancy & $125(96.15)$ \\
& Taking adequate rest during postnatal period & $126(96.92)$ \\
& Practising family planning and birth spacing & $122(93.84)$ \\
& Avoid early pregnancy & $118(90.76)$ \\
Risk factor* & Use of institutional delivery & $116(89.23)$ \\
& Use of safe abortion services & $115(88.46)$ \\
& Many vaginal deliveries & $128(98.46)$ \\
& Adolescent pregnancy & $127(97.69)$ \\
& Obesity & $111(85.38)$ \\
& Increasing age & $100(76.92)$ \\
Malnutrition & $95(73.07)$ \\
& Chronic constipation & $85(65.38)$ \\
& Prior pelvic surgery & $80(61.53)$ \\
\hline
\end{tabular}

*Multiple response

The majority of the participants (129; 96.15\%) reported that difficulty in lifting heavy loads as the main symptom of UP, followed by lower abdominal pain (101; $77.69 \%$ ), sagging uterus (98; $75.38 \%$ ), and odorous

discharge (85; 65.38\%). All participants reported that not lifting heavy loads during the postnatal period, the best method for the prevention of UP, followed by eating nutritious food during pregnancy (125; 96.15\%), taking 
adequate rest during the postnatal period (122; $93.84 \%$ ), and using safe abortion services (115; 88.46\%). Almost all participants (128; 98.46\%) reported that having many vaginal deliveries were risk factors for
UP, followed by adolescent pregnancy $(127 ; 97.69 \%)$, obesity $(111 ; 85.38 \%)$, prior pelvic surgery $(80 ; 61.53 \%)$, as shown in Table 2.

Table 3: Level of knowledge on UP

\begin{tabular}{llc}
\hline Characteristics & Categories & $\mathrm{n}(\%)$ \\
\hline Level of Knowledge & Good $(\geq 75 \%)$ & $55(42.30)$ \\
& Satisfactory $(50$ to $<75 \%)$ & $75(57.69)$
\end{tabular}

More than half of the participants $(75 ; 57.69 \%)$ had a satisfactory level of knowledge, and 55 (42.30\%) had a good level of knowledge on uterine prolapse, while none of them exhibited a poor level of knowledge, as illustrated in Table 3.

Table 4: Factors associated with level of knowledge

\begin{tabular}{lccccc}
\hline \multicolumn{1}{c}{ Characteristics } & \multicolumn{2}{c}{ Level of Knowledge } & odd ratio & $95 \% \mathrm{Cl}$ & P-value \\
\hline Ageod & Satisfactory & & & \\
\hline$<40$ & 40 & 55 & 0.96 & $0.55-1.68$ & $0.014^{\star}$ \\
$\geq 40$ & 15 & 20 & 1 & & \\
$\begin{array}{l}\text { Education } \\
\text { Literate }\end{array}$ & 47 & 59 & 1.59 & $0.78-2.89$ & $0.008^{\star}$ \\
$\begin{array}{l}\text { Illiterate } \\
\text { Occupation }\end{array}$ & 8 & 16 & 1 & & \\
$\begin{array}{l}\text { Employed } \\
\text { Unemployed }\end{array}$ & 16 & 11 & 2.38 & $1.34-4.25$ & $0.03^{\star}$ \\
$\begin{array}{l}\text { Ethnic Group } \\
\text { Advantage }\end{array}$ & 39 & 64 & 1 & & \\
Disadvantage & 43 & 39 & 3.30 & $1.31-4.22$ & $0.024^{\star}$ \\
Heard of UP & 12 & 36 & 1 & & \\
Yes & 45 & 47 & 2.60 & $1.11-3.92$ & $0.017^{\star}$ \\
No & 10 & 28 & 1 & & \\
\hline
\end{tabular}

Bivariate analysis of the outcome variable was performed with other independent variables. Knowledge scores were used to categorize respondents into a binary variable good and satisfactory. The association was considered significant if the " $P$ " value was less than 0.05 . Bivariate analysis of all variables was performed. However, only five independent variables were found to be significantly associated with level of knowledge, which is listed here. Women aged $<40$ years were found 0.96 times more likely to have a good level of knowledge than women who aged $\geq 40$ years. Literate women were found 1.59 times more likely to have a good level of knowledge than illiterate women and advantaged women were found 3.3 times more likely to have a good level of knowledge than disadvantaged women. Similarly, employed women were found 2.86 times more likely to have a good level of knowledge than unemployed women. Likewise, women who had heard about UP were found 2.6 times more likely to have a good level of knowledge than those who had notheard about UP, as shown in Table 4.

\section{Discussion}

The current status of knowledge on UP among women of reproductive age (18 to 50) visiting gynecology OPD of the tertiary care hospital in central Nepal was explored over a period of 3 months among 130 participants. Most of the participants had a primary level of education and were from the central region of the country. Our study showed that $70 \%$ of the participants had heard about UP, and more than half of the participants had satisfactory knowledge. The knowledge in our study population contradicts that of study population of a large-scale study conducted in 25 districts of Nepal and Egypt [2, 15].

Our study showed that mass media were the common source of information for gaining knowledge about uterine prolapse, which is consistent with that of other studies $[2,16]$. This is because, mass media like radio and television are easily accessible tool and are commonly available in the house of people of every socioeconomic background. Our study showed that age, education, ethnic group, and occupation are significantly associated with the level of knowledge 
about uterine prolapse in women. The 2011 Nepal Demography and Health Survey (NDHS 2011) demonstrated that the class, caste/ethnic group, and education are significantly associated with overall health knowledge and reproductive health care-seeking practices [17]. School, magazines, and female community health workers are the major source for obtaining information on health related matters in low economic country like Nepal. However, it is reported that these source do not provide enough information regarding risk factors for uterine prolapse [18]. Subject course in school do not cover adequate information on sexual and reproductive health, which in fact is the most important learning for life time. Additionally, teachers in Nepal feel embarrassed to discuss about it and its prevention. Magazines do not cover the sensitive health problem like uterine prolapse which is the major female health issue in Nepal. Due to this women cannot have enough knowledge on the prevention of uterine prolapse and when it actually happens they hesitate to open up and hide it within themselves thinking everyone will judge them and they will be stigmatized. Thus, inadequate formal education on sexual and reproductive health, lack of focus on prevention of uterine prolapse in community health programs for women might be the reason for current variation seen in the satisfactory level of knowledge about uterine prolapse among female teenagers and other age groups. Similarly, low education level is the major barrier in the ability to utilize available health care service optimally, and this is usually a strong barrier to the use of antenatal and skilled birth services in women in Nepal [18]. Educated women are involved in many health organization which focus on female health as their major project. During their working duration they got to attend seminars and trainings related to uterine prolapse and other female problems, which directly or indirectly contributes in increasing the knowledge level among women. This might be the reason for high level of knowledge being associated with education and employment status found in our study. Moreover, our study showed the significant association between the knowledge level and ethnic group which is consistent with the large scale study conducted in 25 districts of Nepal [2].

The limitation of this study is that: this was a singlecentered study conducted in a single hospital of central Nepal and in a relatively small sample size. Therefore, the generalizability of the findings remains to be explored.

\section{Conclusion}

Our study showed that the level of knowledge on uterine prolapse among women of reproductive age group is satisfactory, and is attributed to their age, education, occupation, and ethnic group. The findings highlight the need for implementation of uterine prolapse related health promotion programs to target women of all caste/ethnic groups, age groups, and education status nationwide.

\section{ACKNOWLEDGMENTS}

We would like to thank Chitwan Medical College Teaching Hospital for providing support to conduct this study.

\section{REFERENCES}

1. Bijalwan RP, Bhagavatula M, Semwal VD, Rawat $P$, Anand V. Morbidity of uterine prolapsed among the women in the chakrata block of Dehradun District. Indian J Community Health 2015; 27: 103-9.

2. Shrestha B, Devkota B, Khadka BB, Choulagai B, Pahari DP, Onta S, Petzold M, Krettek A. Knowledge on uterine prolapse among married women of reproductive age in Nepal. Int $\mathrm{J}$ Women's Health 2014; 6:771.

3. Dhital R, Otsuka K, Poudel KC, Yasuoka J, Dangal G, Jimba M. Improved quality of life after surgery for pelvic organ prolapse in Nepalese women. BMC Womens Health 2013; 13:22. https://doi. org/10.1186/1472-6874-13-22.

4. Shrestha B, Onta S, Choulagai B, Poudyal A, Pahari DP, Uprety A, et al. Women's experiences and health care-seeking practices in relation to uterine prolapse in a hill district of Nepal. BMC Womens Health 2014; 14:20.

5. Khadgi J, Poudel A. Uterine prolapse: a hidden tragedy of women in rural Nepal. IntUrogynecol J 2018; 29(11):1575-8.

6. Bodner-Adler B, Shrivastava C, Bodner K. Risk factors for uterine prolapse in Nepal. IntUrogynecol J 2007; 18:1343-6.

7. Earth B, Sthapit S. Uterine prolapse in rural Nepal: gender and human rights implications. A mandate for development. Cult Health Sex 2002; 4:281-96.

8. Bonetti TR, Erpelding A, Pathak LR. Listening to "felt need": investigating genital prolapse in western Nepal. Reprod Health Matters 2004; 12(23):166-175

9. Fitchett JR, Bhatta S, Sherpa TY, Malla BS, A Fitchett EJ, Samen A, Kristensen S. Non-surgical interventions for pelvic organ prolapse in rural Nepal: a prospective monitoring and evaluation study. JRSM open 2015; 6(12):2054270415608117.

10. Shrestha B, Choulagai B, Onta S, Shrestha KB, Petzold M, Krettek A. Knowledge, prevalence and treatment practices of uterine prolapse among women of reproductive age in the JhaukhelDuwakot Health Demographic Surveillance Site, Bhaktapur, Nepal. JKMC2014; 3(4):136-43.

11. Radl CM, Rajwar R, Aro AR. Uterine prolapse prevention in Eastern Nepal: the perspectives of women and health care professionals. Int $J$ Women's Health2012; 4:373. 
12. Sharma SK, Sawangdee $Y$, Sirirassamee B. Access to health: women's status and utilization of maternal health services in Nepal. J BiosocSci2007; 39(5):671-92.

13. Bodner-Adler B, Shrivastava C, Bodner K. Risk factors for uterine prolapse in Nepal. IntUrogynecol J2007; 18(11):1343-6.

14. Subedi M. Uterine prolapse, mobile camp approach and body politics in Nepal. DJSA 2010; 4:21-40.

15. Goman HM, Fetohy EM, Nosseir SA, Kholeif AE. Perception of genital prolapse: a hospital-based study in Alexandria (Part II). J Egypt Public Health Assoc2001; 76(5-6):337-56.

16. Elsayed F, Ahmed M, Gaheen MA. Knowledge and Practices of women regarding risk factors of uterine prolapse. IOSR Journal of Nursing and Health Science (IOSR-JNHS) 2016; 5(6):60-7.

17. Bennett L. Gender Caste and Ethnic exclusion in Nepal: following the policy process from analysis to action. In: Arusha Conference, "New Frontiers of Social Policy" World Bank ESSD Network, Arusha, December 12-15, 2005; Tanzania. Available from: http://www.k4health.org/sites/default/files/Gender,\% 20caste\%20and\%20ethnic\%20exclusion\%20in\%20N epal.pdf. Accessed September 12, 2020.

18. Amnesty International UK. Nepal: Unnecessary Burden: Gender Discrimination and Uterine Prolapse in Nepal. ASA 31/001/2014. London: Amnesty international Ltd, Peter Benenson House; 2014. Available from: http://www.amnesty.org/en/ library/info/ASA31/001/2014/en. Accessed September 12, 2020. 